\title{
PERAN IBU DALAM TOILET TRAINING PADA ANAK USIA TODDLER DI KECAMATAN KEMLAGI KABUPATEN MOJOKERTO
}

\author{
Veryudha Eka Prameswari ${ }^{1^{*}}$, Indah Kusmindarti ${ }^{2}$, Linda Ajeng Lestari ${ }^{3}$ \\ ${ }^{1 * 2,3}$ Stikes Bina Sehat PPNI Mojokerto, Jawa Timur, email: veryudha_prameswari0485@yahoo.com
}

\begin{abstract}
Background : Toilet training in children was an effort to train children to be able to control the conduct defecation and urination. Exercise of defecation and urination in children need preparation, both physically, psychologically and intellectually, through this preparation expected that child was able to control defecation and urination independently.

Objective : Purpose of this research to describe the role of mother in toilet training on children toddler olds in the Mojodadi village Kemlagi District of Mojokerto.

Methods : Design of research was used descriptive research design. The method of sampling used total sampling (nonprobability sampling). Sample was taken all respondents as many as 82 respondents who have a toddler old of children in the Mojodadi village Kemlagi District of Mojokerto in June 2015. Data was collected by questionnaire instrument and then the data though as editing, coding, scoring, tabulating and was analyzed by $\mathrm{T}$ score then the results presented with Frequency Distribution Table.

Results : The results was showed that the discribe role of mother in the toilet training on children toddler olds in the Mojodadi village Kemlagi District of Mojokerto as the respondents who had a negative role as much as 44 respondents (53.7\%) while having a positive role as much as 38 respondents $(46.3 \%)$.

Conclusions : A negative role due to the lack of information on how to train toilet training and the role of mother is also influenced their knowledge, education, age and occupation held by the respondents related to toilet training.
\end{abstract}

Keywords: Toilet training, role, toddler

\section{PENDAHULUAN}

Toilet training pada anak merupakan suatu usaha untuk melatih anak agar mampu mengontrol dalam melakukan buang air kecil dan buang air besar. Toilet training merupakan salah satu tugas perkembangan anak usia toddler karena pada usia 1-3 tahun kemampuan spinter ani dan spinter urinya mulai berkembang. Latihan buang air kecil dan besar pada anak membutuhkan persiapan baik secara fisik, psikologis maupun secara intelektual, melalui persiapan tersebut diharapkan anak mampu mengontrol buang air besar atau kecil secara mandiri. ${ }^{1}$ Pada toilet training selain melatih anak dalam mengontrol buang air besar dan kecil juga dapat bermanfaat pada pendidikan seks sebab saat anak melakukan kegiatan tersebut disitu anak akan mempelajari anatomi tubuhnya sendiri serta fungsinya. ${ }^{1}$ Fenomena yang terjadi di Mojodadi berdasarkan informasi dari peneliti yang di dapat dari bidan desa yang menyebutkan bahwa kurangnya peran ibu dalam melatih BAB/BAK dan ibu yang selalu memakai pempres pada anaknya. Budaya ibu yang kebanyakan kalau anaknya BAB/BAK tidak di toilet melainkan di depan rumah. Ini yang menyebabkan konsep toilet training dipandang tidaklah penting dalam tahap perkembangan anak usia toddler.

Hasil penelitian Mega Herlina (2013) di Desa Keji Kecamatan Ungkasan Barat Semarang menyatakan 2 anak (20\%) 
BAB/BAK di celana tidak memberitahukan ibunya, 5 anak (50\%) masih memakai pempres setiap hari, 1 anak (10\%) BAB/BAK dengan bantuan orang tua, 2 anak (20\%) sudah bisa melakukan BAB/BAK dengan benar di toilet. $^{2}$

Berdasarkan hasil studi pendahuluan yang dilakukan peneliti di Desa Mojodadi pada tanggal 18 Februari 2015 dengan teknik wawancara pada 8 orang ibu yang mempunyai anak usia 1-3 tahun dan didapatkan bahwa 4 (50\%) ibu memilih memakai pempres dengan alasan karena lebih praktis, 1 (12,5\%) ibu mengatakan bahwa anaknya sudah bisa menerapkan dan memberitahukan ingin BAK dan BAB, 3 $(37,5 \%)$ ibu memakai pempres tiap hari pada anaknya dalam waktu 24 jam.

Toilet training merupakan suatu hal yang dilakukan oleh orang tua pada anak, mengingat dengan latihan ini diharapkan anak mempunyai kemampuan sendiri dalam melaksanakan BAK dan BAB tanpa merasakan ketakutan atau kecemasan sehingga anak akan mengalami pertumbuhan dan perkembangan sesuai usia tumbuh kembang anak. ${ }^{1}$ Agar dapat meningkatkan perannya, ibu harus tahu bagaimana cara melatih anak untuk mengontrol rasa ingin buang air, diantar dengan menggunakan pot kecil yang bisa diduduki anak atau langsung ke toilet pada jam tertentu misalnya setiap dua jam anak di bawah ke toilet untuk berkemih. ${ }^{3}$
Dampak yang paling umum dalam kegagalan toilet training seperti adanya perlakuan atau aturan yang ketat bagi orang tua kepada anaknya yang dapat menganggu kepribadian anak atau cenderung bersifat retentive di mana anak cenderung bersikap keras kepala. Hal ini dapat dilakukan oleh orang tua apabila sering memarahi anak pada saat buang air besar atau kecil, atau melarang anak saat berpergian. Bila orang tua santai dalam memberikan aturan dalam toilet training maka anak akan dapat mengalami kepribadian ekspresif dimana anak lebih tega, cenderung ceroboh, suka membuat gara-gara, emosional dan seenaknya dalam melakukan kegiatan sehari-hari. ${ }^{1}$

Penggunaan toilet training merupakan hal yang perlu mendapat perhatian dari tenaga kesehatan. Dan salah satu tugas yang harus dilakukan untuk keberhasilan toilet training khususnya ibu hendaknya harus memiliki kesabaran dan memiliki pengendalian yang tinggi dalam mengajarkan toilet training pada anak, selain itu seorang ibu harus paham tentang perkembangan atau waktu anak untuk perlu BAB atau BAK, sehingga anak juga akan mudah menerima dan mengikuti apa yang diajarkan kepadanya. Tujuan penelitian ini untuk mengetahui gambaran peran ibu dalam toilet training pada anak usia toddler di Desa Mojodadi Kecamatan Kemlagi Kabupaten Mojokerto. 


\section{BAHAN DAN CARA PENELITIAN}

Desain penelitian yang digunakan dalam penelitian ini adalah desain penelitian deskriptif. Metode sampling yang digunakan adalah nonprobability sampling tipe sampling jenuh (total sampling). Populasi dalam penelitian ini adalah seluruh lbu yang mempunyai anak usia toddler di Desa Mojodadi Kecamatan Kemlagi Kabupaten Mojokerto adalah 82 anak. Sampling pada penelitian ini menggunakan nonprobability sampling tipe sampling jenuh (total sampling) dengan cara seluruh ibu yang mempunyai anak usia toddler di Desa Mojodadi Kecamatan Kemlagi Kabupaten Mojokerto sebanyak 82 orang.Instrumen yang digunakan dalam penelitian ini adalah kuesioner.Dilakukan proses pengolahan data mulai dari editing, coding, scoring,dan tabulating. Setelah data dikumpulkan dilakukan pengukuran dengan menggunakan skor $\mathrm{T}$ dan di sajikan dalam bentuk tabel frekuensi distribusi.

\section{HASIL DAN PEMBAHASAN}

Berdasarkan penelitiaan yang dilakukan pada tanggal 04-09 juni 2015 didapatkan data tentang usia anak. Data yang diperoleh dapat di lihat dalam tabel distribusi frekuensi di bawah ini:

Tabel 1. Distribusi Frekuensi Responden Berdasarkan Jumlah Anak

\begin{tabular}{cccc}
\hline No & $\begin{array}{c}\text { Jumlah } \\
\text { Anak }\end{array}$ & Frekuensi & $\begin{array}{c}\text { Presentase } \\
(\%)\end{array}$ \\
\hline 1 & Anak ke 1 & 28 & $34,1 \%$ \\
\hline 2 & Anak ke 2 & 30 & $36,6 \%$ \\
\hline 3 & Anak $>2$ & 24 & $29,3 \%$ \\
\hline & Total & 82 & $100 \%$ \\
\hline
\end{tabular}

Tabel 2. Distribusi Frekuensi Responden Berdasarkan Usia Ibu

\begin{tabular}{|c|c|c|c|}
\hline No & $\begin{array}{c}\text { Usia } \\
\text { ibu }\end{array}$ & Frekuensi & $\begin{array}{c}\text { Presentase } \\
(\%)\end{array}$ \\
\hline 1. & 18-19 tahun & 12 & $14,6 \%$ \\
\hline 2. & 20-21 tahun & 10 & $12,2 \%$ \\
\hline 3. & $22-23$ tahun & 6 & $7,3 \%$ \\
\hline 4. & 24-25 tahun & 9 & $11,0 \%$ \\
\hline 5. & 26-27 tahun & 8 & $9,8 \%$ \\
\hline 6. & $28-29$ tahun & 9 & $11,0 \%$ \\
\hline 7. & 30-31 tahun & 6 & $7,3 \%$ \\
\hline 8. & $32-33$ tahun & 7 & $8,5 \%$ \\
\hline 9. & 34-35 tahun & 15 & $18,0 \%$ \\
\hline & Total & 82 & $100 \%$ \\
\hline
\end{tabular}

Sumber : Data primer, Juni 2015

Tabel 3. Distribusi Frekuensi Responden Berdasarkan Pendidikan Ibu

No Pendidikan Ibu Frekuensi Presentase

\begin{tabular}{cccc} 
& & & $(\%)$ \\
\hline 1 & Tidak Tamat SD & 0 & 0 \\
\hline 2 & SD & 0 & 0 \\
\hline 3 & SMP & 39 & $47,6 \%$ \\
\hline 4 & SMA & 35 & $42,6 \%$ \\
\hline 5 & Perguruan Tinggi & 8 & $9,8 \%$ \\
\hline & Total & 82 & $100 \%$
\end{tabular}

Sumber : Data primer, Juni 2015

Tabel 4. Distribusi Frekuensi Responden Pekerjaan Ibu

\begin{tabular}{|c|c|c|c|}
\hline No & $\begin{array}{c}\text { Pekerjaan } \\
\text { lbu }\end{array}$ & Frekuensi & Presentase(\%) \\
\hline 1 & Bekerja & 27 & $32,9 \%$ \\
\hline 2 & $\begin{array}{l}\text { Tidak } \\
\text { Bekerja }\end{array}$ & 55 & $67,1 \%$ \\
\hline & Total & 82 & $100 \%$ \\
\hline
\end{tabular}

Sumber : Data primer, Juni 2015

Tabel 5. Distribusi Frekuensi Responden berdasarkan Peran Ibu dalam Toilet Training No Peran lbu Frekuensi Presentase

(\%)

\begin{tabular}{cccc}
\hline 1 & Positif & 38 & $46,3 \%$ \\
\hline 2 & Negatif & 44 & $53,7 \%$ \\
\hline & Total & 82 & $100 \%$ \\
\hline
\end{tabular}

Sumber : Data primer, juni 2015

Hasil penelitian tentang peran ibu dalam toilet training pada anak usia toddler yang dilakukan terhadap 82 responden di 
Desa Mojodadi Kecamatan Kemlagi Kabupaten Mojokerto. Diperoleh data bahwa sebagai besar responden berdasarkan tabel 5 diketahui bahwa yang memiliki peran negatif sebanyak 44 responden $(53,7 \%)$ sedangkan yang mempunyai peran positif sebanyak 38 responden (46,3\%).

Peran adalah kemampuan individu untuk mengontrol atau mempengaruhi atau mengubah perilaku orang lain. Ibu adalah orang yang mempunyai kemungkinan terbesar untuk mengenali anaknya. ${ }^{3}$ Sedangkan teori lain menunjukkan bahwa peran adalah sesuatu yang diharapkan secara normatif dari seseorang dalam situasi sosial tertentu agar dapat memenuhi harapan-harapan. Peran ibu adalah tingkah laku spesifik yang diharapkan oleh seseorang dalam konteks ibu. ${ }^{4}$ Menurut Efendy, beberapa peranan ibu yang terkait adalah untuk mengurus rumah tangga, sebagai pengasuh, pendidik anak-anaknya, pelindung, dan sebagai salah satu kelompok peranan sosialnya serta sebagai masyarakat dari lingkungan. ${ }^{5}$

Berdasarkan tabel 1 karakteristik berdasarkan jumlah anak menunjukkan bahwa jumlah anak hampir setengah responden adalah anak ke 2 sebanyak 30 anak (36,6\%). Jumlah anak yang banyak dan jarak yang terlalu dekat akan mengurangi kasih sayang pada anak. dengan banyaknya anak maka ibu akan mempunyai pengalaman yang cukup dalam melakukan perannya pada keluarga dan anak. ${ }^{3}$ Seharusnya dengan mempunyai lebih banyak anak ibu memiliki pengalaman yang banyak dalam melakukan peran pada anak.

Berdasarkan tabel 2 karakteristik responden berdasarkan usia ibu menunjukkan bahwa sebagian kecil responden adalah berusia 34-35 tahun sebanyak 15 ibu (18,0\%). Usia yang paling memuaskan untuk membesarkan anak adalah usia antara 18-35 tahun, karena pada usia tersebut orang tua masih mempunyai kesehatan optimum dan diperkirakan usia harapan hidup yang memungkinkan waktu yang cukup dan memadai dalam membangun sebuah keluarga. ${ }^{3} \quad$ Usia responden adalah usia yang paling memuaskan karena pada usia tersebut ibu masih mempunyai kesehatan optimal sehingga dapat mengerjakan peran dalam toilet training secara optimal.

Berdasarkan tabel 3 karakteristik responden berdasarkan pendidikan ibu menunjukkan bahwa sebagian besar responden adalah berpendidikan SMP sebanyak 39 ibu (47,6\%). Tingkat pendidikan ibu turut menentukan mudah tidaknya seseorang menyerap dan memahami pengetahuan yang mereka peroleh. Dari kepentingan keluarga pendidikan itu sendiri amat diperlukan seseorang lebih tanggap adanya masalah perkembangan anak salah satunya penerapan toilet training di dalam keluarganya. Tingkat pendidikan berpengaruh pada pengetahuan ibu tentang penerapan toilet training sehingga 
berpengaruh pada cara melatih secara dini penarapan toilet training. ${ }^{6}$ Pendidikan responden yang tergolong rendah membuat mereka lebih sulit menerima informasi atau pengetahuan yang benar, sehingga dapat berpengaruh pada cepat atau lambatnya ibu yang memiliki pengetahuan yang baik tentang toilet training secara dini pada anak usia toddler sehingga menimbulkan peran yang negatif dalamtoilet training.

Berdasarkan tabel 4. karakteristik responden berdasarkanpekerjaan ibu menunjukkan bahwa sebagian besar responden adalah tidak bekerja sebanyak 55 ibu (67,1\%). Menurut Sudilarsih (2010) status pekerjaan ibu mempunyai hubungan yang bermakna dengan toilet training secara dini pada anak usia toddler. ${ }^{6}$ Di mana pekerjaan ibu akan mempengaruhi peran ibu karena waktu yang diberikan tidak maksimal. ${ }^{3}$ Sedangkan jika dilihat dari pekerjaan diketahui sebagian besar responden tidak bekerja atau sebagai ibu rumah tangga seharusnya memiliki banyak waktu dan dapat dilakukan secara maksimal untuk melatih anak melakukan toilet training secara dini sehingga tidak berdampak pada terlambatnya anak untuk mandiri melakukan toilet training.

Hasil penelitian di Desa Mojodadi Kecamatan Kemlagi Kabupaten Mojokerto menunjukkan bahwa sebagian besar ibu memiliki peran negatif. Peran yang diberikan ibu pada anaknya dapat dipengaruhi beberapa faktor berdasarkan pendidikan, pekerjaan, usia ibu dan jumlah anak. Seharusnya dengan pendidikan yang tinggi responden mempunyai pengetahuan yang baik dalam penerapan toilet training. Sebaliknya jika pendidikan yang kurang akan mempengaruhi dalam menerima informasi atau pengetahuanyang benar, sehingga dapat berpengaruh pada cepat atau lambatnya ibu yang memiliki pengetahuan yang baik tentang cara melatih toilet training secara dini pada anak usia toddler. Meskipun seseorang mempunyai pendidikan yang rendah tetapi jika ia mendapatkan informasi yang baik dari mengikuti penyuluhan dari tenaga kesehatan dari media misalnya : TV, radio atau buku, maka hal ini akan dapat meningkatkan pengetahuan seseorang. Lingkungan merupakan salah satu faktor yang mempengaruhi pengetahuan seseorang. Dalam lingkungan seseorang akan memperoleh pengalaman yang berpengaruh pada cara berfikir seseorang. ${ }^{7}$

Jika dilihat dari segi usia, dapat dilihat bahwa usia 18-35 tahun memiliki peran negatif. Seharusnya pada usia tersebut orang tua masih mempunyai kesehatan optimal dalam menjalankan peran ibu dalam toilet training. Sedangkan jika dilihat dari pekerjaan dapat diketahui sebagian besar responden menjadi ibu rumah tangga atau tidak bekerja, seharusnya responden lebih punya banyak waktu untuk mencari informasi baik melalui media sosial ataupun melakukan konseling secara langsung dengan tenaga kesehatan setempat. Hal ini disebabkan karena 
kurangnya informasi dan pengetahuan ibu tentang cara melatih toilet trainingsehingga peran yang di hasilkan sebagian besar adalah negatif.

Saat ini memang tenaga kesehatan yang kurang memberikan penyuluhan atau pendidikan kesehatan pada ibu tentang ilmu kesehatan anak yang berhubungan dengan toilet training supaya ibu dapat mengetahui dan memberi peran yang mendukuang pada anaknya dalam toilet training.

\section{KESIMPULAN}

Peran ibu dalam toilet training pada anak usia toddler di Desa Mojodadi Kecamatan Kemlagi Kabupaten MojokertoTahun 2015 yang dilakukan pada 82 responden di peroleh data bahwa responden yang mempunyai peran negatif sebanyak 44 responden (53,7\%), sedangkan yang mempunyai peran positif sebanyak 38 responden $(46,3 \%)$.

Diharapkan responden agar lebih meningkatkan informasi yang tentang toilet training dengan cara konseling kepada tenaga kesehatan setempat.

Diharapkan bagi petugas kesehatan bersedia memberikan penyuluhan atau pendidikan kesehatan pada ibu tentang ilmu kesehatan anak yang berhubungan dengan toilet training supaya ibu dapat mengetahui dan memberi peran yang mendukuang pada anaknya dalam hal toilet training.

Dalam penelitian ini mungkin masih banyak kekurangan-kekurangan. Untuk itu diharapkan bagi peneliti selanjutnya untuk lebih menambahkan pembahasan yang baru mengenai peran ibu dalam toilet training pada anak usia toddler.

\section{KEPUSTAKAAN}

1. Hidayat, A. A. pengantar ilmu keperawatan 1 anak. jakarta: salemba medika ;2005.

2. Herlina, Mega. hubungan antara pengetahuan dan sikap ibu tentang toilet training dengan praktek pada anak usia toddler di desa keji kecamatan ungaran barat.http://www.perpusnwu.web.id/karyai Imiah/documents/3269.doc;2013

3. Supartini, Y. Buku Ajar Konsep Dasar Keperawatan Anak. Jakarta: EGC;2004

4. Mubarak. Buku Ajar Kebutuhan Manusia. Jakarta:EGC ; 2009

5. Effendy, D. N. Dasar-dasar Keperawatan Kesehatan Masyarakat. Jakarta: EGC ; 2004

6. Sudirlasih, F. Mampu Mengatasi 1001 Masalah Balitah Anda Sehari-hari Orang Tua. Yogyakarta: Graha IImu ; 2010

7. Notoatmodjo, P. Metodologi Penelitian Kesehatan. Jakarta: Rineka Cipta ; 2012 